\title{
ANALYSIS OF AUTOMOTIVE BUMPER FASCIA IN A PASSENGER
}

\section{CAR}

\author{
Avinash Mujagond ${ }^{1}$, Shivanand Kavadimatti ${ }^{2}$, S. N. Kurbet ${ }^{3}$ \\ ${ }^{1,2}$ PG Students Mechanical Department BEC. Bagalkot. \\ ${ }^{3}$ Professor \& HOD Mechanical Department BEC. Bagalkot.
}

\begin{abstract}
Bumpers are vital auxiliary parts of vehicles as far as wellbeing, static quality, and styling. This work depicts different parts of the nonlinear static FEA of vehicle front guards utilizing the business programming Abaqus 6.1, and the connection with physical tests. The essential ideas, systems and procedures of nonlinear FEA are displayed. The impacts of different parts of nonlinear reproductions like numerical coordination, contact parameters, non-conformance of the cross section and material law are considered. A nodally incorporated component definition for plates is proposed for examination, and the plan is actualized in Abaqus 6.1. Numerical tests are completed on the new component. Recommendations are proposed in recreation to enhance the relationship of CAE results with physical test
\end{abstract}

Keywords: Automative Bumper Fascia, Nonlinear FEA, Abaqus 6.1.

\section{INTRODUCTION}

Bumpers are car parts arranged at the front and back of vehicle to guarantee the insurance of a vehicle body if there should be an occurrence of a low speed crash. This is empowered by means of the formability of bumpers and vitality retention amid an effect. The accident ability of the Bumper ought to likewise meet overall directions with respect to the wellbeing of traveler this paper portrays the nonlinear static recreation of firmness performed on a car front Bumper. In this section, a brief prologue to car front Bumpers and to nonlinear static reproduction is exhibited.

\subsection{Bumper}

Bumpers are basic parts introduced at the front and backsides of a vehicle to ensure the auto body, adornments, and travelers amid low-speed impacts. They shape a critical part of the styling of a vehicle, which gives it its one of a kind character.

Different national directions have been instituted concerning the execution of guards under low speed effect, for example, 49 CFR (Code of Federal Regulations) Part 581 of the National Highway Traffic Safety Administration (NHTSA) in the United States, the United Nations Economic Commission for Europe (ECE) control No. 42, and the CMVSS (Canada Motor Vehicle Safety Standard) 215. There are no AIS (Automotive Industry Standards) directions for guards in India starting 2011.

With the expanding accentuation on vitality proficiency in autos because of the increasing expense of fuel, there is a push towards lessening the heaviness of all parts, including guards. The Bumpers should likewise have adequate firmness, and the car maker sets the solidness necessities to be met by the bumper. In this manner, the test in Bumper outline is to keep up a fragile harmony between vehicle weight diminishment, having adequate firmness, and meet wellbeing principles in the meantime. A portion of the basically vital parts of the guard are [4]:

- Fascia: The style component of the Bumper, which is an expansion of the configuration of the vehicle

- Grille: Allows air to enter the motor compartment

- Absorber: Part to absorb part of the vitality discharged upon effect. The safeguard introduced between the bar and belt assimilates the effect vitality. When it is introduced in a structure to be shielded from stun, its weight is not an issue but rather for the most part, there is a constrained configuration space or volume for the safeguard. For the safeguard an auxiliary plastic is utilized with a suitable shape to assimilate vitality.

- Reinforcement: Part to harden the belt of the Bumper and the apparent quality and worth.

The grille and styling is characterized by the customer, while the obligation of the idea and outline of the safeguard, fortifications, and different parts of the Bumper lies with Faurecia.

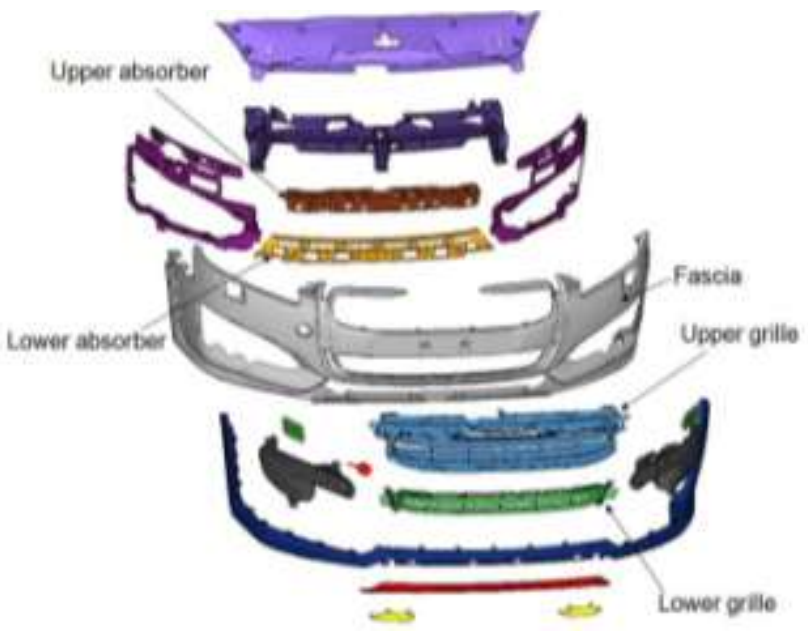

Fig -1. Parts of a front bumper gathering 
Choosing the outside appearance or styling is the initial phase in the configuration, trailed by the idea plan. After this, the computational reproduction investigation of the Bumper can be done. Because of the various and here and there clashing prerequisites of guard configuration, it is key to join Finite Element Analysis, which is today an essential apparatus in car plan, gives exact, practical and dependable results.

\subsection{Nonlinear Static Analysis}

Direct static examination of anxiety is an extremely helpful instrument in mechanical configuration, however it has genuine weaknesses in the investigation of this present reality. It can't precisely anticipate stress when the distortions or redirections surpass little values, and it is not pertinent to building materials like polymers, wood, composites, and so on. Polymers and composites are presently supplanting metals in numerous building applications, in that capacity, the investigation of nonlinearity is basic keeping in mind the end goal to exploit the abilities of advanced structures to convey stacks past the yield point.

Nonlinear investigation is a need in:

- Designing elite and effective parts of specific commercial enterprises (e.g. aviation, protection and atomic)

- Assessing usefulness (e.g., remaining quality and solidness of basic components) of existing frameworks that show some writes of harm and disappointment building up reasons for framework disappointment.

- Simulating genuine material conduct non-metals (plastics, composites, and so forth.)

- Research to pick up a reasonable comprehension of physical marvels.

\section{PROBLEM STATEMENT}

Relationship results watched demonstrate that there is a bungle between the outcomes from the CAE recreation and the physical test outcomes. The relationship results are enhanced to minimize the mistakes between CAE results and physical test outcomes

\subsection{Objectives}

In this study, the attention is on enhancing the precision of the nonlinear static reenactments performed on vehicle front Bumper to assess their solidness and quality. As a part of the study, diverse contact surfaces have been assessed and another component plan has been proposed and executed in Abaqus.

\subsection{Methodology}

The utilization of nonlinear recreations is essential with a specific end goal to reenact the conduct of the Bumper sashes, which are perpetually made of plastic, and which may experience extensive strains and distortions. Before testing the full Bumpers model, beginning tests were done on a straightforward cinched strip model, and connection with test outcomes was gotten. At that point, the Bumper was fit and amassed. In the wake of setting up the FE get together model, the static reenactments were done in the Abaqus solver form 6.1. The physical bumpers get together was tried in the research facility. The impact of contact sorts and numerical parameters identified with the components, for example,the incorporation control and number of reconciliation focuses were examined. The following stride was to rectify any entrances found and enhance the contacts. At last, the cross section was checked for non-conformance to the physical parts and, the impact of the material law incorrectness was contemplated. The outline of the relationship is appeared in Fig. 1.3. After this, another component plan in view of nodal joining is produced and incorporated in Abaqus.

\section{LITERATURE REVIEW}

Golze et al., [1] depicted the configuration of traveler auto bumper so as to meet the Federal Motor Vehicle Safety Standard No. 215 (FMVSS 215), "Outside Protection". The objective was to accomplish a lightweight, minimal effort Bumpers that is good with styling and sufficiently tough to endure almost no harm amid effect at $5 \mathrm{mph}(8 \mathrm{~km} / \mathrm{h})$. Distributed in 1973, this was one of the main papers on vehicle Bumper distributed by the SAE; this was not long after the principal controls in the USA, the aforementioned Federal Standard took impact on 1 September 1972. A PC helped outline procedure was produced which had great relationship with tests.

Look P., [2] displayed a universally useful, PC helped building outline strategy which has been utilized in the configuration of car guard frameworks in 1984. An examination of PC supported investigation forecasts with real test information is displayed. Two case histories of guard framework plans are examined. The PC program CBUMP is depicted, which is utilized to decide guard divider thicknesses utilizing the vitality and energy conditions for effect loads. This is trailed by FEA.

\section{EXPERIMENTAL TESTING OF BUMPER}

The physical tests on the Bumpers were done at the research center of Faurecia Automotive Exteriors. The test conditions for subjective firmness are given by the vehicle maker. They characterize the satisfactory most extreme removal under a characterized exertion, the sort of impactor and the test areas on the bumpers belt. This information will likewise fluctuate according to the bumpers model for the same customer (car, utility, and so forth.) 


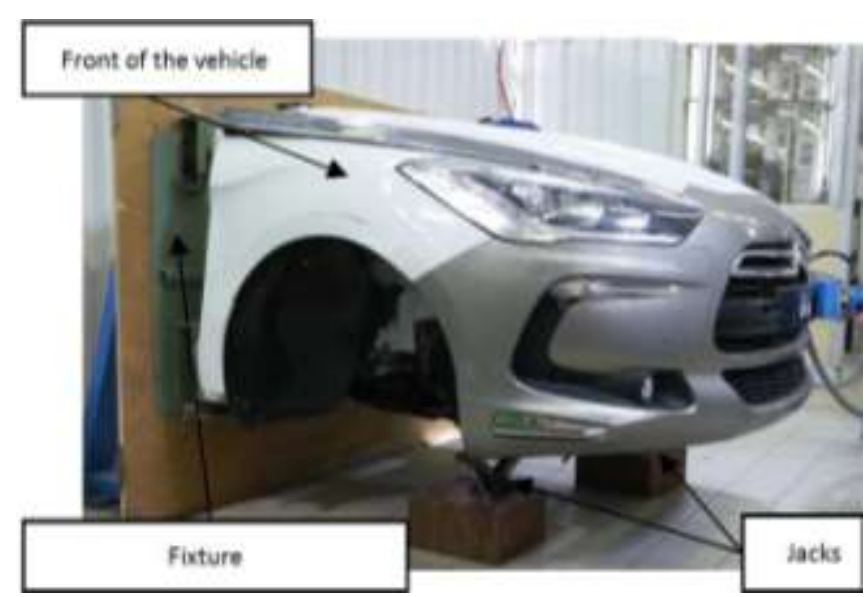

Fig - 2. For test setup of bumper framework

The front or back of a vehicle is cut and mounted on a plaque that can adjust to the game plan of the Faurecia research facility. It is likewise bolstered by two jacks on the base to keep away from over the top vertical development amid the execution of solidness tests. This setup is given by the maker. The bumpers is connected to this unit by means of the standard connection focuses characterized for this reason.
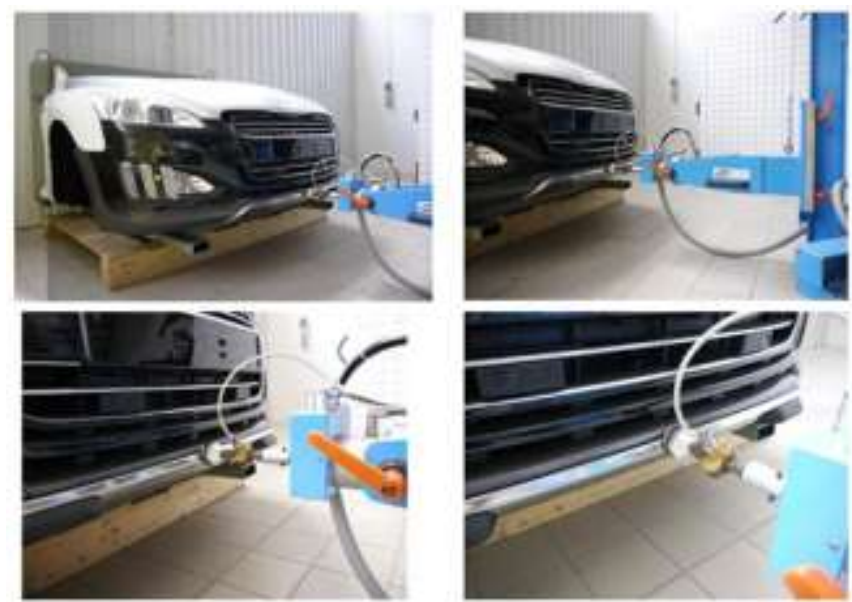

Fig -3. For the testing of bumpers

\section{RESULTS AND DISCUSSIONS}

FEA Results for $250 \mathrm{~N}$ Load

1. First loading condition

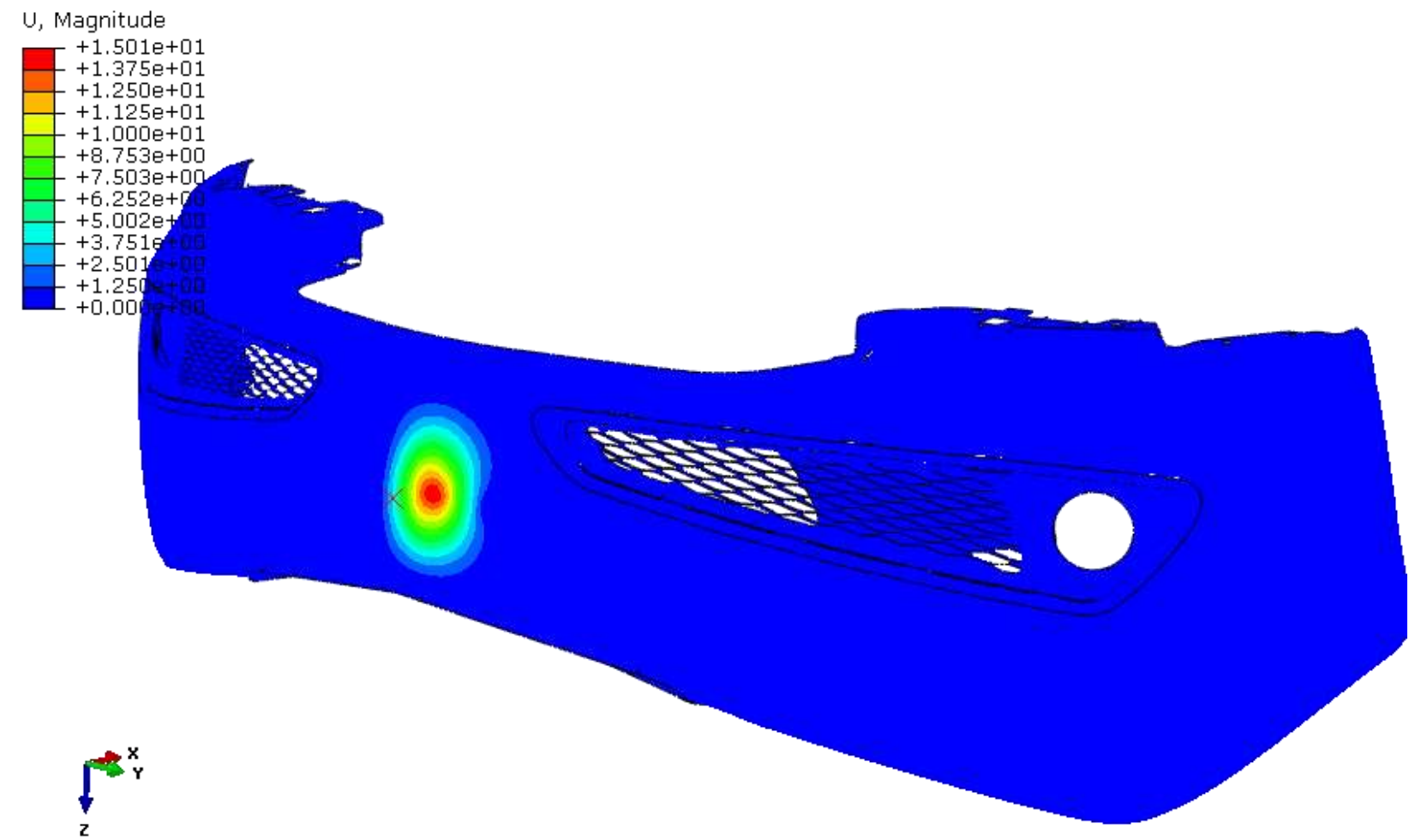

Fig. 4 displacement 


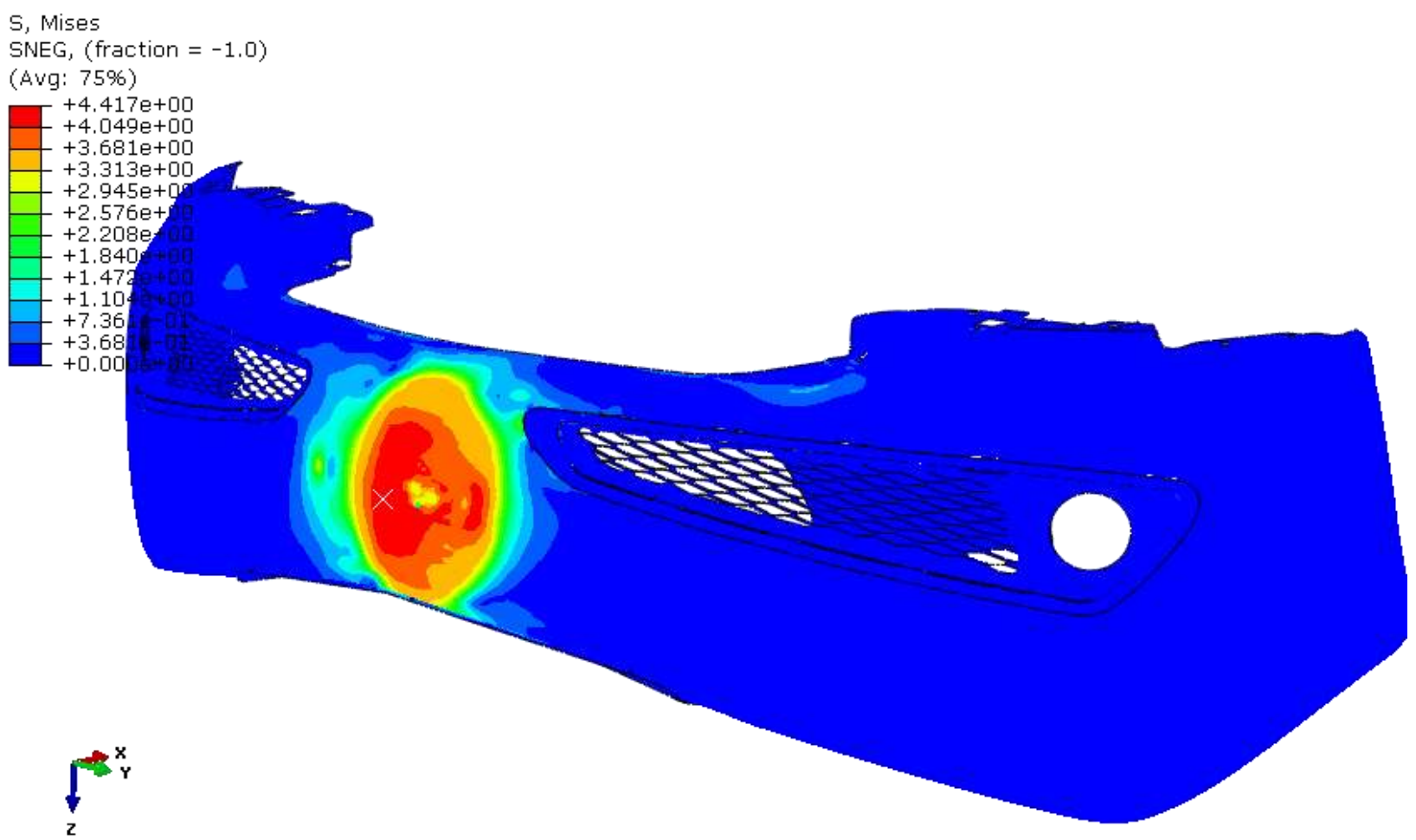

Fig. 5 von misess stress

\section{Second Loading Condition}
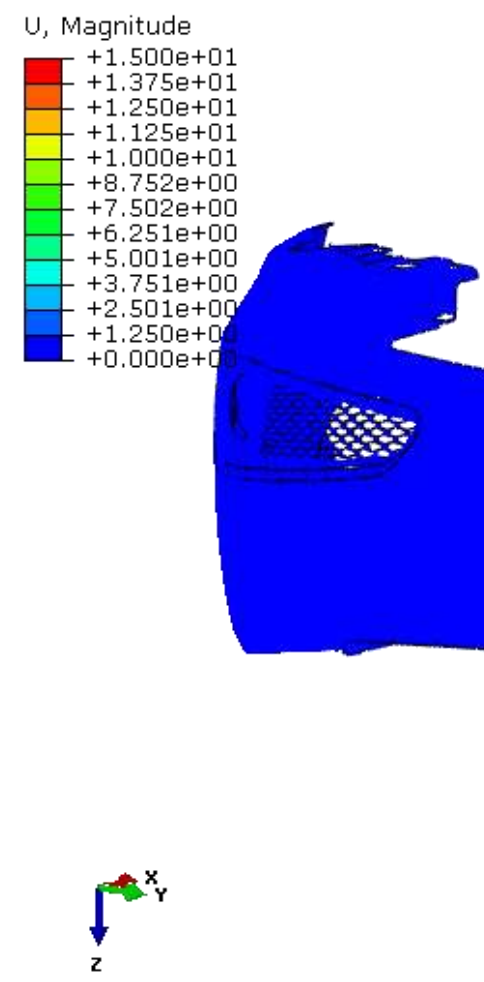

Fig. 6 displacement 
S, Mises

SNEG, (fraction $=-1.0$ )

(Avg: 75\%)

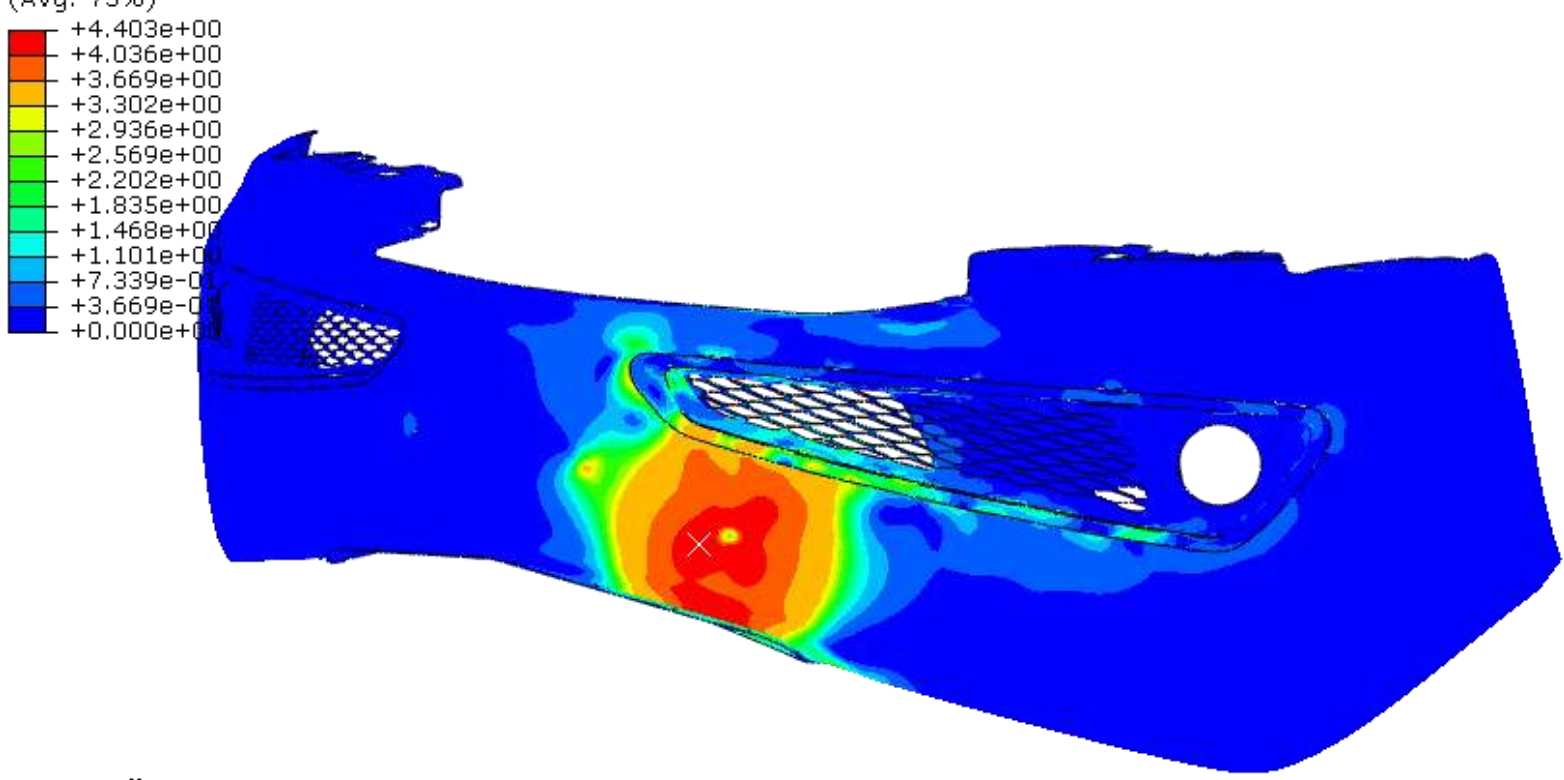

$f_{z}^{x}$

Fig. 7 von misess stress

\section{Third loading condition}

$S$, Mises

SNEG, $($ fraction $=-1.0$ )

(Avg: $75 \%$ )

$+4.408 \mathrm{e}+00$
$+4.041 \mathrm{e}+00$

$+3.673 \mathrm{e}+00$

$+3.306 \mathrm{e}+00$

$+2.939 \mathrm{e}+00$

$+2.571 \mathrm{e}+00$

$+2.204 \mathrm{e}+00$

$+1.837 e+00$

$+1.469 \mathrm{e}+00$

$+1.102 \mathrm{e}+00$

$+7.347 \mathrm{e}-01$

$+3.673 \mathrm{e}-01$

$+0.000 \mathrm{e}+00$
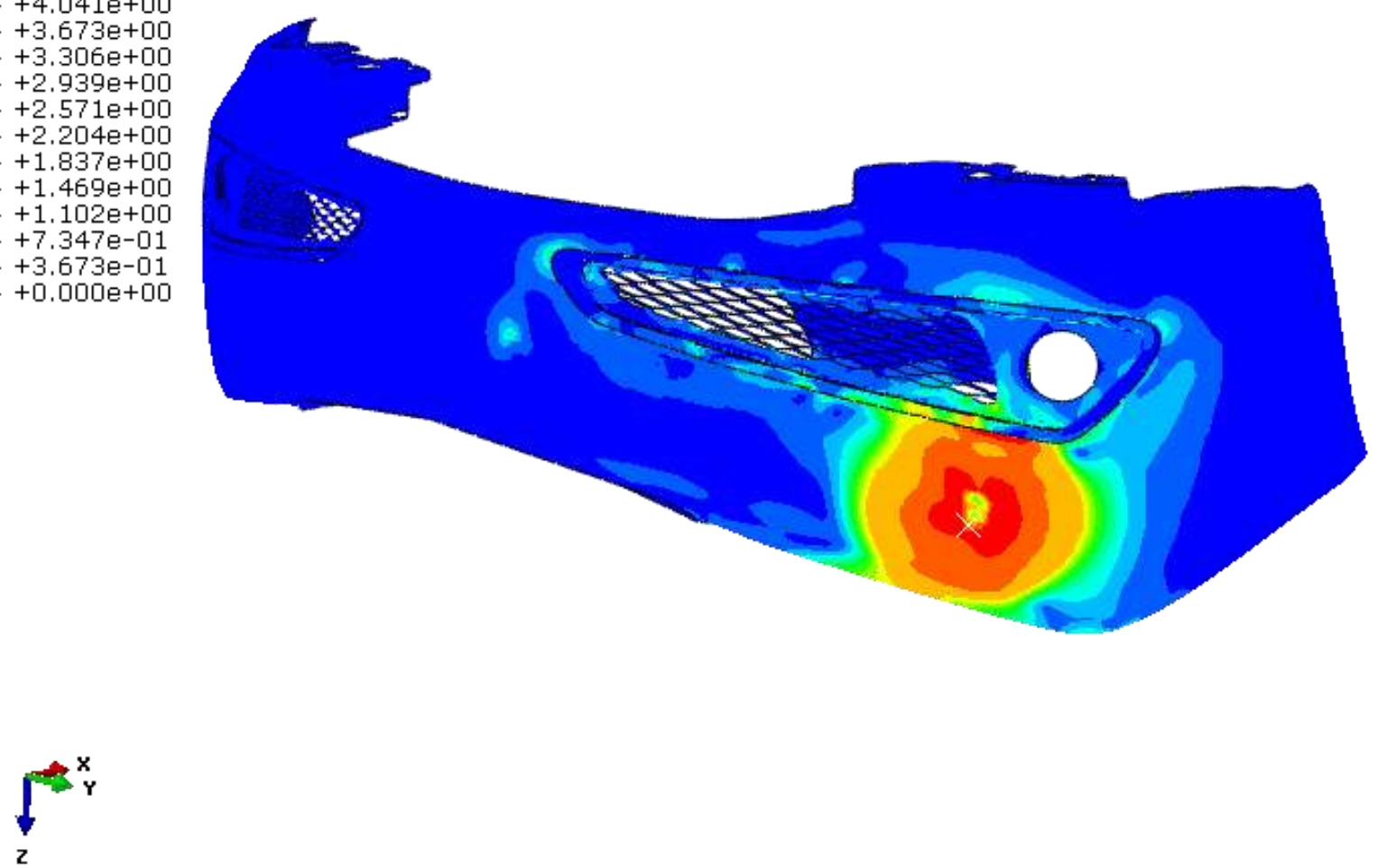

Fig. 8 displacement 


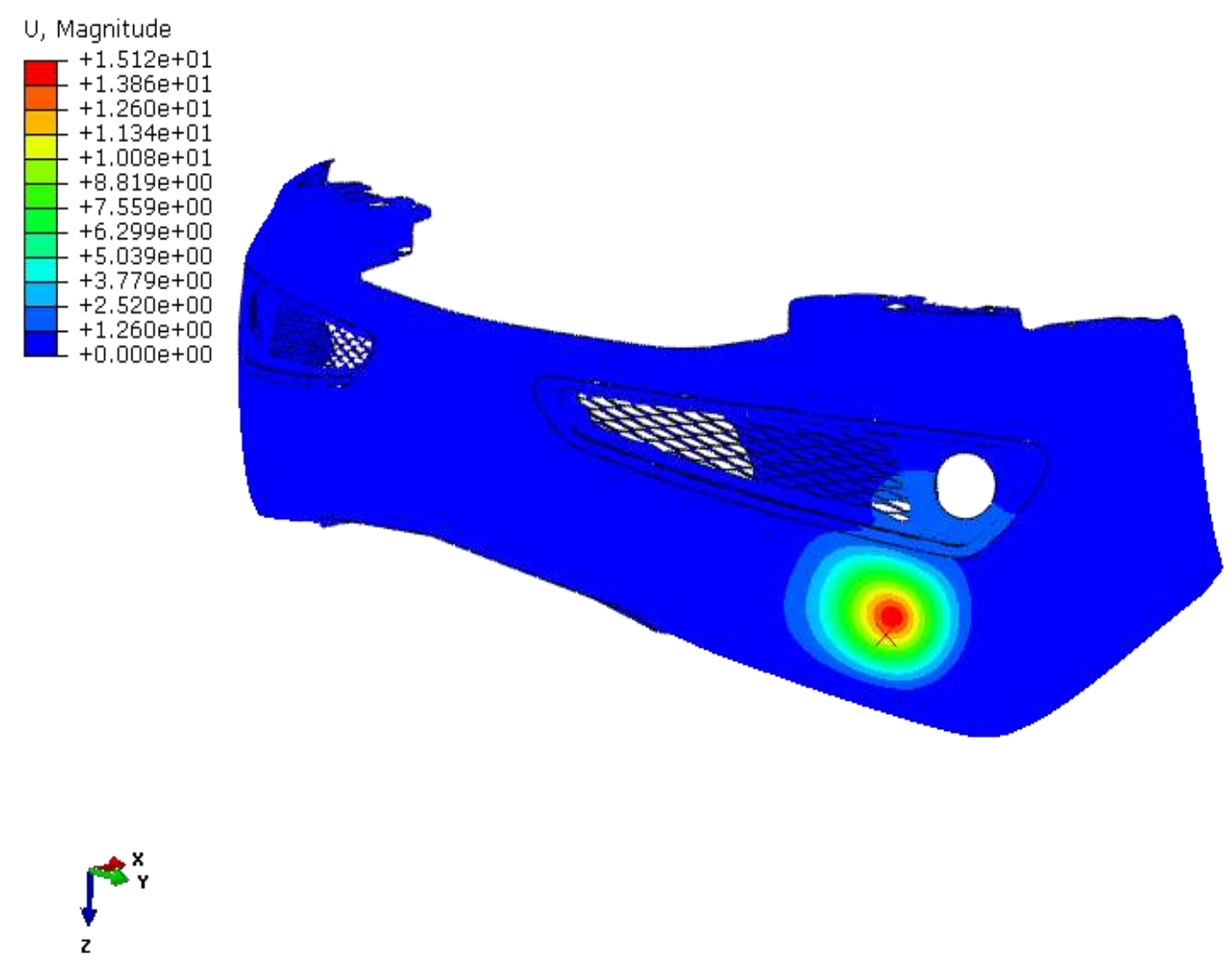

Fig.9 von misess stress

Table1. Comparison for different loading conditions

COPARISON FOR DIFFERENT LOADING CONDITIONS

\begin{tabular}{|l|l|l|l|l|}
\hline $\begin{array}{l}\text { S. } \\
\text { NO }\end{array}$ & $\begin{array}{l}\text { TYE OF } \\
\text { LOADING }\end{array}$ & LOAD & DISPLACEMENT & STRESS \\
\hline 1 & $\begin{array}{l}\text { RIGHT } \\
\text { SIDE }\end{array}$ & $250 \mathrm{~N}$ & 15.1 & 4.147 \\
\hline 2 & MIDDLE & $250 \mathrm{~N}$ & 15 & 4.403 \\
\hline 3 & $\begin{array}{l}\text { LEFT } \\
\text { SIDE }\end{array}$ & $250 \mathrm{~N}$ & 15.12 & 4.408 \\
\hline
\end{tabular}

\section{CONCLUSIONS}

The contact and entrance mistakes, network conformance and material law do effective affect the outcomes. The fundamental driver for non-connection were mistake of contact and entrance displaying, network and conformance blunders and material law distinction. The outcomes enhanced and there a decent relationship of $88 \%$ overall is acquired between the CAE and physical test outcomes when the primary driver of non-connection are dealt with. Rate of mistake is enhanced when contrasted with the past rate of blunder amid connection

\section{REFERENCES}

[1]. Golze R. also, Kienle R., Bumper outline materials and creation, SAE Technical Paper, 1973, pp. 1-8.

[2]. Glance P., Computer helped building examination of car Bumper, SAE Technical Paper, 1984, pp. 2.1-2.8.

[3]. Glance P. also, Daroczy G., Computer-supported configuration examination and testing of car bumper, SAE Technical Paper, 1988, pp. 4.502-4.513.

[4]. Rawson J., Comparison of investigation results to physical testing for the execution of building thermoplastic bumper pillars, SAE Technical Paper, 1994, pp. 81-88.

[5]. Sugimoto Y., Otonari S., Itou H., and Tomizawa H., FEM Analysis of warmth disfigurement of plastic bumper SAE Technical Paper, 1998 